\title{
Note on Texts
}

Because of the number of different contributors to this volume and the large selection of editions of the works of Cervantes available, we have limited citation from Don Quixote to notation by part and chapter number (e.g., II.1o). For other works of Cervantes-for example, the Persiles, stories from the Exemplary Novels, and plays from Cervantes's Interludes-textual references to the Spanish originals are given in the footnotes by each contributor.

All quotations from Cervantes's works appear in both Spanish and English. Unless otherwise noted, the translations into English were supplied by the contributors. Well-known translations of Don Quixote-such as those by John Ormsby, Samuel Putnam, and J. M. Cohen-frequently provided the basis from which modifications and modernizations were made, as indicated by the contributors in each specific case. One contributor was able to consult, in manuscript version, the translation of Don Quixote by Burton Raffel (Bantam, forthcoming 1994). 
